\title{
Demystifying Renal Angina
}

\author{
Sheikh Izzat Bin ZainalAbidin Bahajjaj ${ }^{1}$, Jazli Tan Jia $\mathrm{An}^{1}$, Irfan Abdulrahman Sheth ${ }^{2}$ and \\ Fatimah Lateef ${ }^{3 *}$
}

${ }^{1}$ Medical Student, National University of Singapore, Yong Loo Lin School of Medicine

${ }^{2}$ Senior Staff Registrar, Department of Emergency Medicine, Singapore General Hospital

${ }^{3}$ Senior Consultant and Professor, Department of Emergency Medicine, Singapore General Hospital, Singapore, Yong Loo Lin School of Medicine, National University of Singapore, Lee Kong Chian Medical School, Nanyang Technological University and Duke NUS Graduate Medical School, Singapore

*Corresponding author: Fatimah Lateef, Senior Consultant and Professor, Department of Emergency Medicine, Singapore General Hospital, Singapore, Yong Loo Lin School of Medicine, National University of Singapore, Lee Kong Chian Medical School, Nanyang Technological University and Duke NUS Graduate Medical School, Singapore

\section{ARTICLE INFO}

Received: 幽 July 19, 2021

Published: 幽 July 28, 2021

Citation: Sheikh Izzat Bin Zainal-Abidin Bahajjaj, Jazli Tan Jia An, Irfan Abdulrahman Sheth, Fatimah Lateef. Demystifying Renal Angina. Biomed J Sci \& Tech Res 37(4)-2021. BJSTR. MS.ID.006026.

Keywords: Renal Angina; Renal Attack; Acute Kidney Injury; Biomarkers; Creatinine

\section{ABSTRACT}

Acute Kidney Injury (AKI) is a common phenomenon in the acute as well as inpatient setting, affecting approximately $20 \%$ of patients. AKI is a common complication in critically ill patients worldwide. To prevent and reduce the incidence of severe AKI, risk stratification is deemed important for providing care to patients at high risk of AKI and its downstream complications. Although the Kidney Disease Improving Global Outcomes (KDIGO) guideline defines AKI according to serum creatinine and urine output, serum creatinine is an imperfect marker for detecting severe AKI. New and novel AKI biomarkers are emerging. Thus, prediction of AKI or risk stratification of patients in danger of kidney damage is crucial for initiating preventive measures for AKI. Renal Angina (RA) is a concept developed by Goldstein and Chawla in 2010 as a form to pretest probability assessment for Acute Kidney Injury. Since its conception, Renal Angina has been validated and used in multiple studies; involving paediatric as well as adult patients. However, not many clinicians are well versed on how 'Renal Angina' may be applied in the clinical setting for their patients. The concept of RA involves recognising the risk factors, symptomatology of AKI including serum creatinine, as well as elevated levels of biomarkers for AKI. It is hoped that these will as prolific and become mainstay, as cardiac angina and raised troponins are, in the diagnosis of Acute Coronary Syndrome. In this paper, we summarise and synthesize the concepts surrounding RA, its development, the current applications, benefits, and pitfalls, as well as its use and relevance, moving forwards into the future.

\section{Introduction}

Clinically, the concept of Renal Angina (RA) was put forth to highlight the characteristics of renal injury and to assist in the determination of which patients are at highest risk for Acute Kidney Injury (AKI). It has been used as an analogy, with reference to the concept of angina pectoris, which is used to increase the suspicion of acute coronary syndrome [1,2]. When Goldstein and Chawla first described it, RA drew some parallels from cardiac angina. This was with regards to the combined use of biomarkers (eg. cardiac troponins, CKMB) and clinical signs as well as the risk stratification strategies to diagnose and manage both conditions [2]. With RA, the diagnosis of AKI should be suspected, considering risk factors for kidney injury, symptoms of kidney injury, elevation in serum creatinine as well as increases in AKI biomarkers. RA represents a relatively new, exciting and complex concept that physicians may be less familiar with, compared to cardiac angina [2-4]. There are multiple reasons as to why clinicians and scientists continue to work on and refine the predictive factors for AKI. It serves as an independent risk factor for mortality, increases hospitalization costs and length of stay, as well as ventilator days for critically ill patients in Intensive Care Units (ICU). In fact, AKI increases mortality rates and lengthened ICU stay by fourfold [5,6]. It also increases mortality rates in both adults and children with multiorgan failure, hematopoietic stem-cell or solid-organ transplant, patients on Extracorporeal Membrane Oxygenation (ECMO) and Acute Respiratory Distress Syndrome (ARDS) [4,6-10]. Delayed recognition and diagnosis will contribute significantly to the poor 
outcomes. However, by the time clinicians diagnose AKI, it has often progressed to a state of damage which may not be amenable or reversible to acute intervention. This paper, as a short review, will summarize and synthesize the concepts surrounding RA, its current applications, as well as explore the use and relevance of RA in the future.

\section{Clinical Presentation and Assessment}

The symptoms of AKI are not as distinct and obvious as the spectrum of angina in acute coronary syndrome. This makes it challenging to pick up and diagnose, especially in the acute setting such as the Emergency Department (ED). AKI does not present with overt symptoms like pain, making it difficult to anticipate and alert the clinician of any ongoing injury. The risk factors of AKI must be taken into consideration just as how a patient with significant cardiac risk factors and chest pain are being observed very closely by ED physicians. Patients with the right symptomatology and risk factors for AKI should raise alarm bells, just like in the cardiac patients (Tables $1 \& 2$ ). Astute clinicians will also look for signs such as oliguria, fluid overload and increase in serum creatinine, from the investigations panel. Unlike chest pain in ACS, as AKI is more silent, it is hence more commonly missed. Furthermore, AKI, in the critically ill such as in the context of multiple trauma or serious emergencies and the more complex presentations of patients in the ED, often presents at a more advanced stage of the disease. It is important to understand that AKI is part of a spectrum of disease severity affecting the kidney, and the early detection of AKI via the understanding of the concept of RA, may help reduce or even prevent progression injury and complications. AKI is also noted to be more common in critically ill patients, affecting as high as about $35 \%$ of the patients in the ICU context $[5,6,11,12]$.

\section{Pathophysiology}

The pathophysiology of AKI is complex and multifactorial. Generally, the aetiologies and subsequent mechanism of injury can be differentiated into pre-renal, intra-renal, and post-renal causes [5]. This classification is also often used by clinicians. Pre-renal causes account for the majority of AKI. In pre-renal AKI, hypoperfusion and decreased renal perfusion or reduced renal blood flow is the underlying mechanism. The common aetiologies include hypovolemia from blood loss, other causes of fluid loss including diarrhoea, dehydration, and vomiting. In addition, causes of reduced cardiac output (eg. heart failure, cardiomyopathy, cardiac tamponade) could also lead to hypo-perfusion. The spectrum of shock caused by a variety of factors can also contribute to hypovolemia and hypo-perfusion states. The kidneys are extremely sensitive to these perfusion changes and alterations as they receive roughly $25 \%$ of the total cardiac output $[6,11]$.

Intra-renal causes of AKI can be further classified into four different categories based on the anatomical subdivisions. Damage to the renal tubules, glomerulus, interstitium, and vasculature of the kidney are the main groups of causes. Tubular damage usually results from ischemia, or nephrotoxic injury mostly caused by nephrotoxic medications. Glomerular injury can occur in acute Glomerulonephritis (GN). Injury to the interstitium can be the result of hypersensitivity and inflammatory reactions to medications which are very commonly prescribed, such as antibiotics like penicillin, sulpha based drugs, and cephalosporins $[11,12]$. Post-renal causes of AKI can be caused by an obstruction to either the upper or lower urinary tract. Obstruction will lead to increased pressure in the collecting system which contributes to the inflammatory process, decreased blood flow and eventually, kidney injury. Patients with urological conditions such as large obstructing calculi or external obstruction, caused by large intra-abdominal or pelvic tumours re at risk for this [6,12].

\section{Biomarkers in AKI}

The search for the ideal biomarker/s for AKI continues to interest many researchers and scientists. Some have referred to this AKI biomarker quest as the "search for the renal troponin I". The interest remains high because if there exist such a biomarker, earlier detection, diagnosis and thus, interventions can be instituted appropriately and perhaps the incidence of AKI, which may potentially progress to Chronic Kidney Disease (CKD) and at times, to end stage kidney failure can be lowered [5,12]. The diagnosis of AKI is traditionally dependent on the changes in Serum Creatinine (SCr), a marker which has been shown to have limitations based on factors such as time, body habitus, sex, age, steady-state measurements, and other patient factors. The rise in $\mathrm{SCr}$ is not immediate upon insult to the kidneys. Moreover, as there are no specific symptoms, the diagnosis of AKI is often delayed, thus creating a significant barrier to effective early intervention. At times, for patients whose kidney function is being monitored at intervals, small increments in SCr may not be acted upon immediately by the clinician. However, it has been noted that even small increases in SCr (of the magnitude $0.3 \mathrm{mg} / \mathrm{dl}$ ) may reflect significant kidney damage and can be associated with poor patient outcomes. As a result, intensive research efforts have been expended to identify the novel AKI biomarkers that can assist to direct and determine appropriate therapy which can be instituted perhaps even prior to a rise in $\mathrm{SCr}[3-5,13]$.

The assessment of AKI with the concept of RA utilizes risk factors as well as novel biomarkers (Tables 1 and 2). It has been found that there is an increase in serum or urine concentration of these biomarkers that can pick up early injuries to the kidneys, even before a rise in serum creatinine can be detected $[7,12,14]$. Neutrophil Gelatinase-Associated Lipocalin (NGAL) is currently the most commonly used biomarker. Other biomarkers such as KIM-1 (Kidney Injury Molecule-1), L-FABP (Liver-type Fatty Acid Binding 
Protein), IL-18 (Interleukin-18) are also available currently, but may not be used as frequently. Across several studies, the use of these biomarkers were tested for its sensitivity for AKI. The utility,

Table 1: Established Risk Factors of Acute Kidney Injury (AKI). sensitivities, setting and limitations of some of these studies are summarised in Table 3 [14-34].

\begin{tabular}{|c|c|c|}
\hline Demographic & Past Medical history & Exposures \\
\hline Age $>65$ & Hypertension & Cepsis / Septic shock \\
\hline Female & Chronic Kidney Disease & Volume depletion \\
\hline & Diabetes Mellitus & Nephrotoxic exposure \\
\hline & Ischemic Heart Disease & Mechanical ventilation \\
\hline & Cardiac surgery & Vasopressors \\
\hline
\end{tabular}

Table 2: Comparison of Cardiac and Renal Angina.

\begin{tabular}{|c|c|c|}
\hline & ACS / Cardiac Angina & AKI / Renal Angina \\
\hline Definition & $\begin{array}{l}\text { The spectrum of unstable angina, non-ST-elevation AMI } \\
\text { and ST-elevation AMI initiated due to plaque rupture }\end{array}$ & $\begin{array}{l}\text { An increase in basal serum creatinine of at least } 0.3 \mathrm{mg} / \mathrm{dl} \\
\qquad \text { within } 48 \mathrm{hrs} \text {. } \\
\text { A decrease in creatinine clearance of at least } 50 \% \text {, } \\
\text { The need for renal replacement therapy and Urine output of } \\
\text { less than } 400-500 \mathrm{ml} / \text { day or }<0.5 \mathrm{ml} / \mathrm{kg} / \mathrm{hr} \text { for } 6 \mathrm{hrs} \text {. }\end{array}$ \\
\hline Risk Factors & $\begin{array}{c}\text { Diabetes mellitus } \\
\text { Hypertension } \\
\text { Hyperlipidemia } \\
\text { Family history in first degree relatives } \\
\text { Smoking } \\
\text { Obesity }\end{array}$ & $\begin{array}{c}\text { Increased age } \\
\text { Diabetes mellitus } \\
\text { Liver cirrhosis and liver failure } \\
\text { Congestive heart failure } \\
\text { Sepsis } \\
\text { Exposure to nephrotoxins } \\
\text { Volume depletion } \\
\text { Cardio-pulmonary bypass time }\end{array}$ \\
\hline Clinical Symptoms & $\begin{array}{l}\text { Chest pain (angina) } \\
\text { Angina equivalent } \\
\text { A small proportion may be 'silent' or secondary AMI }\end{array}$ & $\begin{array}{l}\text { Usually silent or asymptomatic } \\
\text { Presentation may be linked to other primary causes like } \\
\text { volume depletion, sepsis, congestive heart failure }\end{array}$ \\
\hline Biomarkers & $\begin{array}{l}\text { Usually: Troponins } \\
\text { Others: CKMB, Myoglobin, other inflammatory markers }\end{array}$ & $\begin{array}{c}\text { Some examples: } \\
\text { IL-18 (interleukin -18) } \\
\text { NGAL(neutrophil gelatinase associated lipocalin) } \\
\text { KIM-1(Kidney Injury Molecule-1) }\end{array}$ \\
\hline Other Investigations & $\begin{array}{c}\text { Electrocardiography } \\
\text { Echocardiography } \\
\text { Angioplasty } \\
\text { Stress Test } \\
\text { Functional and perfusion scans }\end{array}$ & $\begin{array}{l}\text { Cardiac output assessment } \\
\text { Urine assessment: electrolytes, cells, sediments } \\
\text { AKI Renal imaging }\end{array}$ \\
\hline Management/ Therapy & $\begin{array}{l}\text { Acute or delayed PCI } \\
\text { Appropriate Medications including thrombolytic agents } \\
\text { and antiplatelet } \\
\text { Cardiac Rehabilitation } \\
\text { Regular follow up }\end{array}$ & $\begin{array}{c}\text { Early goal directed therapy } \\
\text { Minimize nephrotoxic exposures } \\
\text { Evaluate treatable causes } \\
\text { Fluid management } \\
\text { Optimize hemodynamics } \\
\text { Consider early Renal Replacement Therapy }\end{array}$ \\
\hline
\end{tabular}


Table 3: Summary of biomarkers for AKI and their sensitivities across several studies.

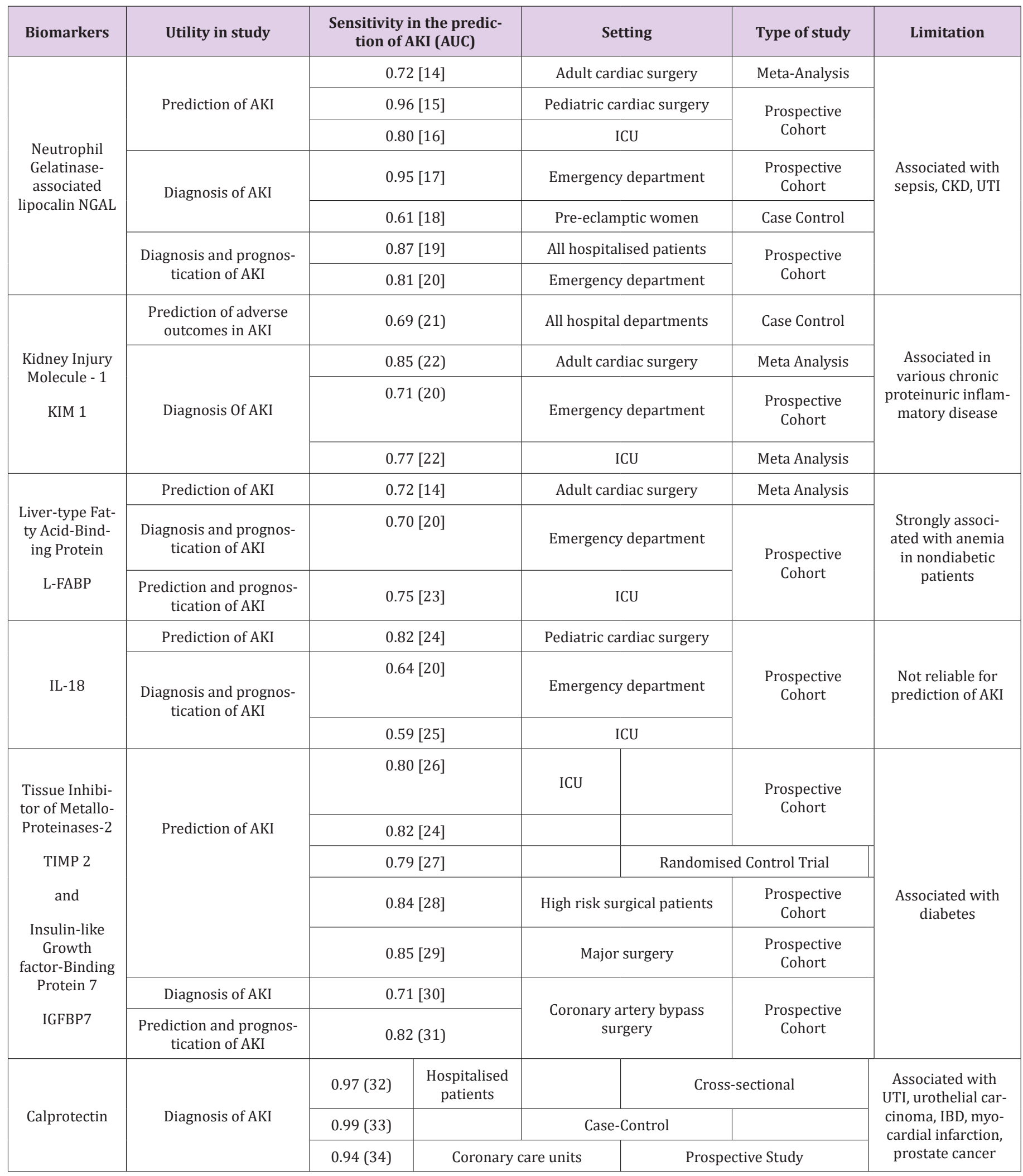

NGAL (Neutrophil Gelatinase-Associated Lipocalin) is a protein associated with human neutrophil gelatinase found in certain granules. The homodimeric form is produced by neutrophils whilst the monomeric and heterodimeric forms are produced by proximal tubular epithelial cells. NGAL stimulates epithelial growth and protects the epithelium against ischemia. Injury to the renal tubular epithelial cells causes NGAL to be released into the urine and plasma before serum creatinine increases can be detected. Other 
than predicting AKI, NGAL is also a good prognostic marker in AKI for mortality and requirement of dialysis [35-37]. KIM-1 (Kidney Injury Molecule-1) is a proximal tubule apical transmembrane protein. Its level increases with inflammation and fibrosis. In ischemic and toxic renal injuries, the extracellular domain of KIM-1 is separated from the membrane, resulting in a 100-fold increase in urinary KIM-1 levels [38-41]. In patients undergoing cardiac surgery, KIM-1 was useful in predicting the prognosis of stage 1 and stage 3 AKI [38]. Additionally, when used together with NGAL, it was able to predict dialysis requirement and hospital mortality in 201 patients with AKI in on study [41].

IL-18 (Interleukin-18) is a cytokine that is cleaved off by the enzyme, caspase-1, and released by monocytes and macrophages. It is produced by the intercalated cells of the collecting ducts in kidneys and injured tubular epithelial cells [13]. Urinary IL18 was found to increase significantly more in comparison with "prerenal azotemia", urinary tract infections, chronic renal failure and nephrotic syndrome [42-44]. L-FABP (Liver-type Fatty AcidBinding Protein) belongs to a family of carrier proteins for fatty acids. It helps regulate fatty acid uptake and intracellular transport. It is expressed in the liver, stomach, intestine, lung and kidney. L-FABP is a sensitive early biomarker of AKI in paediatric patients post cardiopulmonary bypass surgery. Increased levels were also associated with poor prognosis and renal replacement therapy in patients with impaired renal function. In patients with early AKI, urinary L-FABP can also use to improve the prediction of AKI progression, the need for dialysis, and mortality [45-48].

TIMP-2 (Tissue Inhibitor of MetalloProteinases-2) and IGFBP7 (Insulin-like Growth Factor-Binding Protein 7) are two novel biomarkers that, when used together, have been noted to have good predictive value for AKI. They are expressed in the tubular cells in response to damage. In a study with 1000 critically ill patients at risk for AKI, TIMP-2 and IGFBP7 outperformed existing markers including NGAL, KIM-1, IL-18 and L-FABP [26]. However, another study amongst 94 ICU patients, found that TIMP-2 and IGFBP7 levels did not differ between patients who developed AKI and patients who did not [49]. Calprotectin is a heterodimer made up of two monomers, namely, S100A8 and S100A9. Epithelial cells of the renal collecting ducts were shown to produce the two monomers in response to even unilateral ureteral obstruction. In iatrogenic renal ischemic reperfusion injury, the level of urine calprotectin rose some 69 -fold, staying elevated until the fifth postoperative day $[33,34]$. Urine calprotectin has also been used in differentiating pre-renal AKI from intrinsic AKI [32-34,47,48].

In general, the uses of many of these newer biomarkers are not widely available across all centres. Thus, there is currently, no standardized set of testing package recommended for specific groups of patients. What exist is more likely institution or department-based guidelines to approach some of these patients presenting, especially in the acute setting. The cost for many of these biomarkers remain high and thus is not part of the routine tests readily available to patients. Moreover, as we have seen in the literature, the diagnostic accuracy of these tests remains variable and no perfect set of biomarkers have been put forth for specific groups of patients with AKI. Across the world, patients are not presenting early enough and many do not have regular screening despite having multiple risks factors for AKI. It will also be obvious that whereas ECG and cardiac markers may be on the general health assessment package for people who opt for 'health screening', it is not the same for renal assessment. The latter are often not included in these screening packages. At most, usually only a simple point of care urine 'Dipsticks' assessment is included. If we do reach the stage where the cost can be managed, perhaps in the near future, a combined biomarkers package can be suggested for certain groups of patients, especially those at risk. It really comes down to the right combination of diagnostic capabilities, cost effectiveness and not using these biomarkers test indiscriminately [49-51].

\section{Current Applications}

Since the original paper was published [2], there have been attempts at applying the concept of RA in the clinical setting [9,10,49,52-54]. Most notable, the Renal Angina Index (RAI) in children was proposed [10,52-54]. A similar type of index for adults was also being put forth to detect early signs of persistent AKI [9,27,40,55-57]. Despite being tested on several cohort of patients, mostly in the west, the validation of the RAI still lags behind amongst Asian patients. The RAI was derived by combining risk factors and clinical signs of AKI. Basu et al. provided the reasoning for this such that 'as a patient achieves higher risk they require less "clinical signs of AKI" early on to fulfil the criteria for renal angina'. They also concluded that "if a patient has less risk but shows more overt signs of clinical AKI signs, renal angina would also be fulfilled". They used the RAI to improve the prediction of AKI in paediatric patients. This involves a scoring system involving risk stratification, changes in creatinine clearance and fluid overload status. The total score ranges from 1-40, whereby, a score of more than or equal to 8 fulfils the criteria of RA [10,52].

Abbasi et al. conducted a systematic review on the prediction of AKI in children [53]. The collation of data from a total of 11 studies, with 3701 children showed that the RAI has a sensitivity and specificity of $85 \%$ and $79 \%$ respectively, in predicting AKI in children [53]. In a very recently published study by Hanson et al. the authors formulated an "Acute" RAI to be used in the ED setting, in a pilot study with 118 paediatric patients. The study found that their RAI had a negative predictive value of $99 \%$ and a sensitivity of $94 \%$, suggesting that a negative RAI has the potential to rule out AKI in the ED setting [58]. Goldstein et al. is currently improving on the current models of RAI by including urine NGAL measurements to guide clinicians with regards to fluids use, diuretics and dialysis 
initiation for patients with high risk of kidney injury [54]. Cruz et al. looked at the risk factors and small increases in creatinine in a prospective study of 506 ICU patients [9]. The observed sensitivity of RAI was 92\%, and the negative predictive value was 99\% [9]. Matsuura et al. used a modified RAI in critically ill patients. This modified RAI did not include fluid overload in the equation, but used only serum creatinine change in the assessment. The study found that in adults, the modified RAI model only had an AUC (Area Under the Curve, c-statistic) of 0.63. However, when the study included the biomarker L-FABP, the AUC went up to 0.81, which supported the concept that biomarkers may be useful in RA [55]. Some authors also looked at different combination of biomarkers with the RAI and their predictive performance. For example, Basu et al. compared (RAI+Elastase-2), (RAI+Matrix Metalloproteinase-8) as well as (RAI+Elastase-2+MMP-8) and found that the probability of AKI were $27.3 \%, 24.1 \%$ and $31.4 \%$ respectively [52]. Even as these biomarkers may add value, we may still find this not as discerning as we would like it to be, especially in the clinical setting.

There are many patients presenting to the emergency department daily, with a myriad of comorbidities and illnesses. Early detection of AKI through RA has the potential to prevent progression and complications of renal injury. It would be worthwhile for physicians to always keep in mind the possibility of RA in patients, especially those who are critically ill or who have significant risk factors. Therefore, a thorough history and physical examination exercise should always be carried out to ascertain the patient's symptoms and risk factor profile. One must have a high index of suspicion for patients who are severely ill or who need to be sent to the ICU as AKI is especially common in these groups of patients. Other risk factors also need to also be considered as it may be likely that these patients are unable to communicate as well at presentation due to Altered Mental States (AMS). This would make physical examination and vital parameters essential in the assessment of these patients. The presence of raised jugular venous pressure, leg swelling, or weight gain would alert the physician into the possibility of renal angina. Furthermore, urine output should be strictly monitored, looking out for oliguria and decreased urine output (Figure 1).

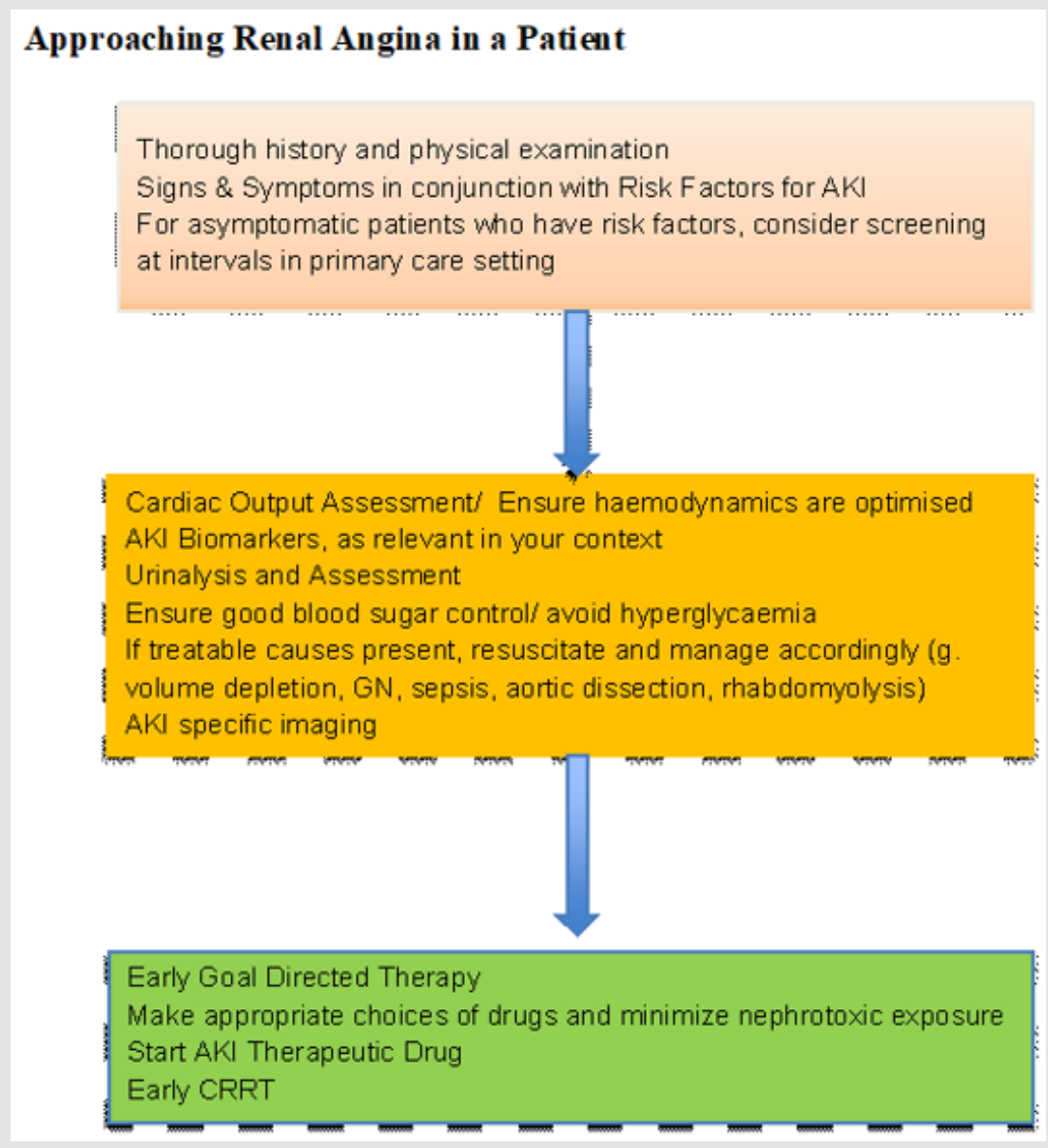

Figure 1: A simplified approach to the potential Renal Angina patient. 
In addition, laboratory tests help guide the clinician in this process. With the risk factors and physical examination findings, serum creatinine and the renal biomarkers should be ordered appropriately. Serum creatinine is a well-known marker of kidney injury. Small increases in serum creatinine can be an early sign of AKI. Serum and urine biomarkers as discussed above should also be assessed if available, and if the overall clinical picture points towards progression of kidney injury, formal evaluation and subsequent management for AKI should begin (Figure 1). Currently, the mainstay of management includes fluid therapy, identification and avoidance of nephrotoxic medication, and escalation of therapy with Renal Replacement Therapy (RRT). Early identification of atrisk patients especially in the Emergency Department (ED) will allow for earlier intervention and identification of reversible causes of AKI, as well as increase confidence for step up therapy to RRT if indicated [54,55,57-59] (Figure 1).

Even as RA seems promising in its future applications, there are possible factors to consider when using RA in the assessment of patients. Firstly, RA considers that small elevations in serum creatinine can be an early marker of AKI. However, there are many other factors that can affect creatinine values, including laboratory error. Furthermore, normal values of creatinine will vary especially in children of different ages, body weight and sizes, compared to adults, where the reference values of creatinine are more accurately predictable. In addition, several variations of the RAI have been used across studies, and thus more research needs to be conducted before a standardized application of RA can be formalized and broadly applied, across different cohorts of patients and different ethnic groups and countries.

\section{Conclusion}

Renal Angina is a relatively new and promising concept that may shift the paradigm of AKI as we progress into the future. New and emerging studies and trials of putting RA into practice have shown some reliable and encouraging results, with RA being a useful tool for both "rule in", as well as "rule out" kidney injury in patients [59]. Although currently not widely applied, the understanding of RA still has value in raising the index of suspicion of AKI and is worth understanding and familiarizing ourselves with, in order to aid in early interventions where appropriate.

\section{References}

1. Levey AS, James MT (2017) Acute Kidney Injury. Ann Intern Med 167(9): Itc66-Itc80.

2. Goldstein SL, Chawla LS (2010) Renal angina. Clin J Am Soc Nephrol 5(5): 943-949.

3. Vanmassenhove J, Kielstein J, Jones A (2017) Management of patients at risk of AKI. Lancet 389(10084): 2139-2151.

4. Chawla LS, Goldstein SL, Kellum JA, Ronco C (2015) Renal angina: concept and development of pretest probability assessment in AKI. Critical Care 19(1): 93.
5. Ronco C (2013) Kidney attack : overdiagnosis of AKI or comprehensive definition of acute kidney syndromes? Blood Purif 36(2): 65-68.

6. Martin RK (2010) Acute kidney injury: advances in definition, pathophysiology, and diagnosis. AACN Adv Crit Care 21(4): 350-356.

7. Zappitelli M (2008) Epidemiology and diagnosis of acute kidney injury. Semin Nephrol 28(5): 436-446.

8. Askenazi DJ, Ambalavanan N, Hamilton K, Cutter G, Laney D, et al. (2010) Acute kidney injury and renal replacement therapy independently predict mortality in neonatal and pediatric noncardiac patients on extracorporeal membrane oxygenation. Pediatr Crit Care Med 12(1): e1-e6.

9. Cruz DN, Ferrer Nadal A, Piccinni P, Goldstein SL, Chawla LS, et al. (2014) Utilization of Small Changes in Serum Creatinine with Clinical Risk Factors to Assess the Risk of AKI in Critically lll Adults. Clinical Journal of the American Society of Nephrology 9(4): 663-672.

10. Basu RK, Zappitelli M, Brunner L, Wang Y, Wong HR, et al. (2014) Derivation and validation of the renal angina index to improve the prediction of acute kidney injury in critically ill children. Kidney Int 85(3): 659-667.

11. Basile DP, Anderson MD, Sutton TA (2012) Pathophysiology of acute kidney injury. Compr Physiol 2(2): 1303-1353.

12. Bellomo R, Kellum JA, Ronco C (2012) Acute kidney injury. The Lancet $380(9843): 756-766$.

13. Siew ED, Ware LB, Ikizler TA (2011) Biological markers of acute kidney injury. J Am Soc Nephrol 22(5): 810-820.

14. Ho J, Tangri N, Komenda P, Kaushal A, Sood M, et al. (2015) Urinary, Plasma, and Serum Biomarkers' Utility for Predicting Acute Kidney Injury Associated with Cardiac Surgery in Adults: A Meta-analysis. Am J Kidney Dis 66(6): 993-1005.

15. Dent CL, Ma Q Dastrala S, Bennett M, Mitsnefes MM, et al. (2007) Plasma neutrophil gelatinase-associated lipocalin predicts acute kidney injury, morbidity and mortality after pediatric cardiac surgery: a prospective uncontrolled cohort study. Crit Care 11(6): R127.

16. de Geus HR, Bakker J, Le Saffre EM, le Noble JL (2011) Neutrophil gelatinase-associated lipocalin at ICU admission predicts for acute kidney injury in adult patients. Am J Respir Crit Care Med 183(7): 907914.

17. Nickolas TL, O Rourke MJ, Yang J, Sise ME, Canetta PA, et al. (2008) Sensitivity and specificity of a single emergency department measurement of urinary neutrophil gelatinase-associated lipocalin for diagnosing acute kidney injury. Ann Intern Med 148(11): 810-819.

18. Moyake N, Buchmann E, Crowther NJ (2016) Neutrophil gelatinaseassociated lipocalin as a diagnostic marker of acute kidney injury in preeclampsia. J Obstet Gynaecol Res 42(11): 1483-1488.

19. Singer E, Elger A, Elitok S, Kettritz R, Nickolas TL, et al. (2011) Urinary neutrophil gelatinase-associated lipocalin distinguishes pre-renal from intrinsic renal failure and predicts outcomes. Kidney Int 80(4): 405-414.

20. Nickolas TL, Schmidt Ott KM, Canetta P, Forster C, Singer E, et al. (2012) Diagnostic and prognostic stratification in the emergency department using urinary biomarkers of nephron damage: a multicenter prospective cohort study. J Am Coll Cardiol 59(3): 246-255.

21. Xie Y, Wang Q, Wang C, Qi C, Ni Z, et al. (2016) High urinary excretion of kidney injury molecule-1 predicts adverse outcomes in acute kidney injury: a case control study. Crit Care 20(1): 286.

22. Shao X, Tian L, Xu W, Zhang Z, Wang C, et al. (2014) Diagnostic value of urinary kidney injury molecule 1 for acute kidney injury: a metaanalysis. PLoS One 9(1): e84131. 
23. Doi K, Negishi K, Ishizu T, Katagiri D, Fujita T, et al. (2011) Evaluation of new acute kidney injury biomarkers in a mixed intensive care unit. Crit Care Med 39(11): 2464-2469.

24. Bihorac A, Chawla LS, Shaw AD, Al Khafaji A, Davison DL, et al. (2014) Validation of cell-cycle arrest biomarkers for acute kidney injury using clinical adjudication. Am J Respir Crit Care Med 189(8): 932-939.

25. Nisula S, Yang R, Poukkanen M, Vaara ST, Kaukonen KM, et al. (2015) Predictive value of urine interleukin-18 in the evolution and outcome of acute kidney injury in critically ill adult patients. Br J Anaesth 114(3): 460-468.

26. Kashani K, Al Khafaji A, Ardiles T, Artigas A, Bagshaw SM, et al. (2013) Discovery and validation of cell cycle arrest biomarkers in human acute kidney injury. Crit Care 17(1): R25

27. Hoste EA, McCullough PA, Kashani K, Chawla LS, Joannidis M, et al (2014) Derivation and validation of cutoffs for clinical use of cell cycle arrest biomarkers. Nephrol Dial Transplant 29(11): 2054-2061.

28. Meersch M, Schmidt C, Van Aken H, Martens S, Rossaint J, et al. (2014) Urinary TIMP-2 and IGFBP7 as early biomarkers of acute kidney injury and renal recovery following cardiac surgery. PLoS One 9(3): e93460.

29. Gocze I, Koch M, Renner P, Zeman F, Graf BM, et al. (2015) Urinary biomarkers TIMP-2 and IGFBP7 early predict acute kidney injury after major surgery. PLoS One 10(3): e0120863.

30. Wetz AJ, Richardt EM, Wand S, Kunze N, Schotola H, et al. (2015) Quantification of urinary TIMP-2 and IGFBP-7: an adequate diagnostic test to predict acute kidney injury after cardiac surgery? Crit Care 19(1): 3.

31. Pilarczyk K, Edayadiyil Dudasova M, Wendt D, Demircioglu E, Benedik J, et al. (2015) Urinary [TIMP-2]*[IGFBP7] for early prediction of acute kidney injury after coronary artery bypass surgery. Ann Intensive Care 5(1): 50 .

32. Heller F, Frischmann S, Grunbaum M, Zidek W, Westhoff TH (2011) Urinary calprotectin and the distinction between prerenal and intrinsic acute kidney injury. Clin J Am Soc Nephrol 6(10): 2347-2355.

33. Seibert FS, Pagonas N, Arndt R, Heller F, Dragun D, et al. (2013) Calprotectin and neutrophil gelatinase-associated lipocalin in the differentiation of pre-renal and intrinsic acute kidney injury. Acta Physiol (Oxf). 207(4): 700-708.

34. Chang CH, Yang CH, Yang HY, Chen TH, Lin CY, et al. (2015) Urinary Biomarkers Improve the Diagnosis of Intrinsic Acute Kidney Injury in Coronary Care Units. Medicine (Baltimore) 94(40): e1703.

35. Andreucci M, Faga T, Pisani A, Perticone M, Michael A (2017) The ischemic/nephrotoxic acute kidney injury and the use of renal biomarkers in clinical practice. European Journal of Internal Medicine 39: $1-8$

36. Haase M, Bellomo R, Haase-Fielitz A (2010) Neutrophil gelatinase associated lipoclin. Curr Opin Crit Care 16(6): 526-532.

37. Devarajan P (2007) Emerging biomarkers of AKI. Contrib Nephrol 156 203-212.

38. Moon SJ, Park HB, Yoon SY, Lee SC (2013) Urinary biomarkers for early detection of recovery in patients with acute kidney injury. J Korean Med Sci 28(8): 1181-1186.

39. Tanase DM, Gosav EM, Radu S, Costea CF, Ciocoiu M, et al. (2019) The Predictive Role of the Biomarker Kidney Molecule-1 (KIM-1) in Acute Kidney Injury (AKI) Cisplatin-Induced Nephrotoxicity. Int J Mol Sci 20(20): 5238.

40. Koyner JL, Vaidya VS, Bennett MR, Ma Q Worcester E, et al. (2010) Urinary Biomarkers in the Clinical Prognosis and Early Detection of Acute Kidney Injury. Clinical Journal of the American Society of Nephrology 5(12): 2154-2165.
41. Liangos O, Perianayagam MC, Vaidya VS, Han WK, Wald R, et al. (2007) Urinary N-Acetyl- $\beta$-(D)-Glucosaminidase Activity and Kidney Injury Molecule-1 Level Are Associated with Adverse Outcomes in Acute Renal Failure. Journal of the American Society of Nephrology 18(3): 904-912.

42. Schrezenmeier EV, Barasch J, Budde K, Westhoff T, Schmidt Ott KM (2017) Biomarkers in acute kidney injury - pathophysiological basis and clinical performance. Acta Physiol (Oxf) 219(3): 554-572.

43. Parikh CR, Jani A, Melnikov VY, Faubel S, Edelstein CL (2004) Urinary interleukin-18 is a marker of human acute tubular necrosis. American Journal of Kidney Diseases 43(3): 405-414.

44. Kashani K, Cheungpasitporn W, Ronco C (2017) Biomarkers of acute kidney injury: the pathway from discovery to clinical adoption. Clin Chem Lab Med 55(8): 1074-1089.

45. Negishi K, Noiri E, Doi K (2009) Monitoring of urinary L-type fatty acid binding protein predicts histological severity of AKI. Am J Pathol 174(4): 1154-1159.

46. Kashani K, Al Khafaji A, Ardiles T, Artigas A, Bagshaw SM, et al. (2013) Discovery and validation of cell cycle arrest biomarkers in human acute kidney injury. Crit Care 17(1): R25.

47. Parikh CR, Garg AX (2018) Acute kidney injury: Better biomarkers and beyond. Kidney Int 73(7): 801-803.

48. Molitoris BA, Melnikiv VY, Okusa MD, Himmerfarb J (2008) Technological insights: Biomarkers development in AKI: what can we anticipate. Nat Clin Pract Nephrol 4(3): 154-165.

49. Bell M, Larsson A, Venge P, Bellomo R, Mårtensson J (2015) Assessment of cell-cycle arrest biomarkers to predict early and delayed acute kidney injury. Dis Markers 2015: 158658.

50. Prowle JR, Kirwan CJ, Bellono R (2014) Fluid management for the prevention and attenuation of AKI. Nat Rev Nephrol 10(1): 37-47.

51. Van Biesen W (2017) Con: Cautionary takes and reservations about the adoption of new technologies and biomarkers for the management of AKI. Nephrol Dial Transplant 32(3): 414-417.

52. Basu RK, Wang Y, Wong HR, Chawla LS, Wheeler OS, et al. (2014) Incorporation of biomarkers with the RAI for prediction of severe AKI in critically ill children. Clin J Am Nephrol 9(4): 654-662.

53. Abbasi A, Mehdipour Rabori P, Farajollahi R, Mohammed Ali K, Ataei N, et al. (2020) Discriminatory Precision of Renal Angina Index in Predicting Acute Kidney Injury in Children; a Systematic Review and Meta-Analysis. Arch Acad Emerg Med 8(1): e39.

54. Goldstein SL (2018) The Renal Angina Index to Predict Acute Kidney Injury: Are Adults Just Large Children? Kidney Int Rep 3(3): 516-518.

55. Matsuura R, Srisawat N, Claure Del Granado R, Doi K, et al. (2018) Use of the Renal Angina Index in Determining Acute Kidney Injury. Kidney Int Rep 3(3): 677-683.

56. Hoste EAJ, Bagshaw SM, Bellomo R (2015) Epidemiology of AKI in critically ill patients: The multinational AKI-EPI Study. Intensive care Med 41(8): 1411-1423.

57. Fletchet M, Guiza F, Schetz M (2017) AKI predictor, an online prediction calculator for AKI in adult critically ill patients: developing, validating and comparison to serum NGAL. Intensive Care Med 43(6): 764-773.

58. Hanson HR, carlisle MA, Bensmen RS, Byczkewski T, Depinet H, et al. (2021) Early prediction of paediatric AKI for the emergency department: a pilot study. The Am Journal of Emergency Medicine 40: 138-144.

59. Farrar A (2018) Acute Kidney Injury. Nursing Clinics of North America 53(4): 499-510. 
ISSN: 2574-1241

DOI: 10.26717/BJSTR.2021.37.006026

Fatimah Lateef. Biomed J Sci \& Tech Res

(C) (P) This work is licensed under Creative BY Commons Attribution 4.0 License

Submission Link: https://biomedres.us/submit-manuscript.php

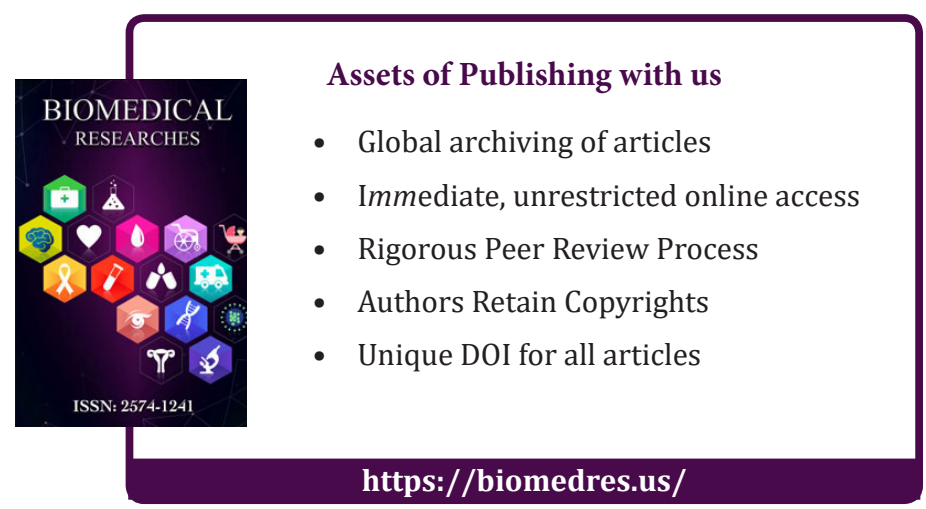

